\title{
Continuous retrograde blood cardioplegia is associated with lower hospital mortality after heart valve surgery
}

\author{
Willem J. Flameng, MD, $\mathrm{PhD}^{\mathrm{a}}$ \\ Paul Herijgers, MD, PhD \\ Sarah Dewilde, $\mathrm{MSc}^{\mathrm{b}}$ \\ Emmanuel Lesaffre, $\mathrm{PhD}^{\mathrm{b}}$
}

From Cardiac Surgery and Biostatistical Centre, ${ }^{\text {b }}$ Katholieke Universiteit Leuven, Belgium.

Received for publication March 22, 2002; revisions requested June 13, 2002; revisions received June 21, 2002; accepted for publication July 15, 2002.

Address for reprints: W. Flameng, MD, $\mathrm{PhD}$, Department of Cardiac Surgery, U.Z. Gasthuisberg, Herestraat 49, 3000 Leuven, Belgium (E-mail: Willem.Flameng@med. kuleuven.ac.be)

J Thorac Cardiovasc Surg 2003;125:121-5

Copyright (C) 2003 by The American Association for Thoracic Surgery

$0022-5223 / 2003 \$ 30.00+0$

doi: $10.1067 / \mathrm{mtc} .2003 .77$

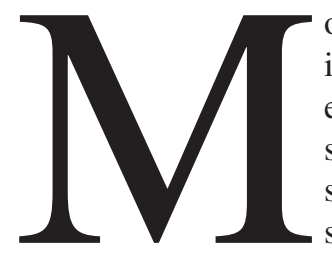

ost clinical studies on cardioplegia techniques have been done in patients undergoing coronary artery bypass grafting. Nevertheless, the advent of off-pump coronary artery bypass surgery has reduced the necessity for it. On the contrary, few studies have been performed in patients undergoing valve surgery in which cardioplegia is still fundamental. There is a wide range of cardioplegia practices with significant intersurgeon and international differences. Major controversies involve the temperature of cardioplegic solutions, intermittence of delivery, and direction of flow. Properly designed randomized clinical trials would be the ideal method for testing the outcome of different methods of myocardial protection, but in cardiac surgery most improvements occurred because of progressive changes in current practice. In the early 1990s, the most common technique used in Europe was cold antegrade crystalloid cardioplegia. In the United Kingdom, for example, in 1992, 58\% of the surgeons used crystalloid cardioplegia, $77 \%$ used antegrade cardioplegia, and $98 \%$ used cold cardioplegia. ${ }^{1}$

Because experimental studies showed that blood cardioplegia was advantageous over crystalloid cardioplegia, ${ }^{2}$ blood cardioplegia gained interest. Obviously, excellent protection can be obtained with the use of cold, ${ }^{3}$ warm, ${ }^{4,5}$ and tepid ${ }^{6,7}$ cardio- 
TABLE 1. Type of intervention

\begin{tabular}{|c|c|c|c|c|c|}
\hline & \multicolumn{2}{|c|}{ Crystalloid } & \multicolumn{2}{|c|}{ Blood } & \multirow[b]{2}{*}{ Total } \\
\hline & -CABG & + CABG & -CABG & + CABG & \\
\hline \multicolumn{6}{|l|}{ Single valve } \\
\hline Aortic & 120 & 138 & 130 & 140 & 528 \\
\hline Mitral & 67 & 69 & 76 & 74 & 286 \\
\hline Tricuspid & 6 & 2 & 1 & 0 & 9 \\
\hline Double valve & 55 & 26 & 79 & 42 & 202 \\
\hline Triple valve & 6 & 5 & 25 & 4 & 40 \\
\hline Bentall + other complex & 8 & 2 & 22 & 1 & 33 \\
\hline Total & 262 & 242 & 333 & 261 & 1098 \\
\hline
\end{tabular}

$C A B G$, Coronary artery bypass grafting.

plegia. Furthermore, the rate of administration of cardioplegia (continuous or intermittent) seemed to matter more than the means of administration (antegrade or retrograde).

In our institution, before November 7, 1994, we used antegrade, single-shot cold crystalloid cardioplegia for all isolated valves or valves combined with coronary bypass operations. At this date, we switched to continuous cold retrograde blood cardioplegia. Because all the patients were operated on at one institution by one surgeon (W.F.) and because the patient population was not supposed to have changed dramatically over time, we decided to analyze, in a retrospective way, early outcome in more than 1000 cardiac valve operations. The objective of the study was to ascertain whether the use of continuous retrograde blood cardioplegia improved our results in terms of hospital mortality.

\section{Methods \\ Patient Population}

The study consists of 1098 consecutive adult patients operated on by one surgeon (W.F.) at the KULeuven between November 4, 1991, and September 18, 1997. Nine hundred thirty-eight underwent primary operations, and 160 underwent reoperations. All patients undergoing valve surgery solely or combined with coronary bypass grafting were included. The type of valve surgery and its distribution between the groups is listed in Table 1. Excluded were interventions with deep hypothermia and circulatory arrest, cardiac transplantations, and non-valve-related operations. Twenty percent of the valve procedures were reconstructions.

From November 4, 1991, until November 6, 1994, all patients $(\mathrm{n}=504)$ were operated on with antegrade cold hyperkalemic crystalloid cardioplegia ${ }^{8}$ combined with topical cooling of the heart. From November 7, 1994, until September 18, 1997, all patients $(\mathrm{n}=594)$ were operated on with retrograde cold blood cardioplegia. The distribution of the type of interventions did not significantly differ between the patient populations (ie, the crystalloid or blood cardioplegia groups $(P>.05)$. However, there was a tendency to operate on more double-, triple-, and complex valve cases in the most recent series. Also, patient characteristics differed between the groups: New York Heart Association (NYHA) function class, body mass index (BMI), incidence of pulmonary hypertension, and arterial hypertension were higher in the blood cardioplegia group, and incidence of angina was lower $(P<.05)$.

\section{Cardioprotective Methods}

As mentioned above, single-shot crystalloid cardioplegia was used before November 6, 1994, in 504 consecutive patients. This hyperkalemic cardioplegic ${ }^{9}$ solution was delivered only by means of antegrade infusion in the aortic root until septal temperature reached $8^{\circ} \mathrm{C}$. A minimum of $800 \mathrm{~mL}$ was used. Cooling of the heart was maintained by means of topical application of slush ice. The crystalloid cardioplegia was basically an oxygenized hyperkalemic solution. General cooling was applied to a rectal temperature of $28^{\circ} \mathrm{C}$. No multidose methods were used. In cases of significant aortic regurgitation, direct coronary perfusion was used.

After November 6, 1994, retrograde blood cardioplegia was used in 594 consecutive patients. A mixture of 3 volumes of blood and one volume of crystalloid cardioplegia ${ }^{9}$ was infused at a temperature of $10^{\circ} \mathrm{C}$ through the coronary sinus at a rate of 300 $\mathrm{mL} / \mathrm{min}$ until the septal temperature reached $15^{\circ} \mathrm{C}$ and cardioplegic arrest was obtained. Then the infusion rate was diminished to a minimum dose, allowing continuous cardiac arrest. General cooling was applied to $28^{\circ} \mathrm{C}$.

\section{Statistical Methods}

$\chi^{2}$ Tests and Student unpaired $t$ tests were used to evaluate differences between the blood and crystalloid cardioplegia groups in terms of patient characteristics, operative data, and mortality. $\chi^{2}$ Tests and Student unpaired $t$ tests were used to evaluate differences between the dead and surviving patients in terms of patient characteristics and operative data. The variables included were age, BMI, sex, left ventricular function, aortic crossclamp time, cardiopulmonary bypass (CPB) time, smoking, diabetes, renal failure, arterial hypertension, pulmonary hypertension, transient ischemic attack, cardiovascular accident, chronic obstructive lung disease, NYHA class, reoperation, myocardial infarction, angina, cardiogenic shock, heart rhythm, aneurysm of ascending aorta, type of operation (valve, valve plus coronary artery bypass grafting, or ascending aorta replacement), aortic valve replacement, mitral valve replacement, tricuspid valve replacement, active infectious endocarditis, associated procedures, emergency status, number of coronary vessels diseased, left main stem lesion, type of cardioplegia, and mortality.

A logistic regression was used to establish the relationship between hospital mortality and the covariates. Because this is not a randomized study, an additional multivariate logistic regression approach was used in which a propensity score model was used to 
correct for imbalances in preoperative variables between the groups. ${ }^{10}$ Extensive preparative modeling with propensity score models with continuous propensity scores or divided into 5 quintiles, with models based on of all or only the most significant differences between the 2 treatment groups, was performed and checked for being multicolinear. After this preparative modeling, a propensity score model was built on the basis of the preoperative variables that differed between the treatment groups at a $P$ value of less than .1 (BMI, sex, CPB, arterial hypertension, pulmonary hypertension, NYHA class, angina, and mitral valve replacement). In the propensity score model we included the 8 main effects and all 2-factor interactions and the squares of each effect, which amounted to 36 variables altogether. We divided the predictive values from this model, the propensity scores, into 5 quintiles. The final model to predict mortality is based on these quintiles together with a stepwise selection of all significantly different variables between the 2 mortality groups (age, BMI, left ventricular function, CPB, aortic crossclamp, renal failure, active endocarditis, NYHA class, reoperations, cardiogenic shock, heart rhythm, aortic aneurysm, type of operation, tricuspid valve replacement, ascending aorta replacement, combined carotid artery surgery, emergency, number of coronary vessels diseased, left main stem lesion, and type of cardioplegia management). All statistical analyses were performed with SAS software.

\section{Results}

\section{Operative Characteristics}

Mean \pm SD aortic crossclamp time was not different between the treatment groups: $76.7 \pm 25.7$ minutes in the crystalloid cardioplegia group and $76.0 \pm 30.5$ minutes in the blood cardioplegia group $(P=.66)$. CPB time, however, was significantly shorter in the blood cardioplegia group (110.0 \pm 43.6 minutes) than in the crystalloid cardioplegia group $(125.5 \pm 44.1$ minutes, $P<.0001)$.

\section{Prediction of Hospital Mortality}

Univariate analysis. The relationship between hospital mortality and the following categoric variables was univariately analyzed: blood cardioplegia, age, sex, BMI, diabetes, type of operation, preoperative NYHA function class, left ventricular function score, renal insufficiency, pulmonary hypertension, arterial hypertension, active endocarditis, reoperation, angina, cardiogenic shock, aneurysm of the ascending aorta, carotid artery surgery, emergency conditions, number of coronary vessels diseased, left main stem lesion, crossclamp time, CPB time, and cardiac rhythm. The nonuse of blood cardioplegia resulted in a hospital mortality of $8.5 \%$ versus $5.2 \%$ when blood cardioplegia was used $(P=.03)$. Furthermore, patients who died were significantly older, had worse ventricular function, had longer aortic crossclamp and CPB times, had more renal failure, had more active endocarditis, had a higher NYHA class, had received more often a previous cardiovascular intervention, were more often in cardiogenic shock $(P<.001)$, had a pacemaker rhythm preoperatively $(P<.01)$, more fre- quently had aorta ascendens replacements $(P<.02)$, needed more tricuspid valve replacement or carotid artery surgery $(P<.01)$, had a significantly higher number of diseased coronary vessels $(P<.001)$, were more likely to have a left main stem stenosis $(P<.02)$, and underwent additional coronary artery bypass grafting surgery $(P<.02)$.

Multivariate analysis. Stepwise selection of all significantly different variables between the 2 mortality groups yielded the following effects: CPB time $\left(\chi^{2}=58.55, P<\right.$ $.001)$, NYHA class $\left(\chi^{2}=14.38, P<.001\right)$, age $\left(\chi^{2}=\right.$ $15.13, P<.001)$, active endocarditis $\left(\chi^{2}=9.43, P=.002\right)$, reoperation $\left(\chi^{2}=7.15, P=.007\right)$, blood cardioplegia $\left(\chi^{2}=\right.$ $6.03, P=.014)$, and renal failure $\left(\chi^{2}=5.51, P=.019\right)$. As a result, our final model to estimate mortality will contain these variables: CPB time, age, NYHA class, active endocarditis, reoperation, renal failure, and blood cardioplegia. We then add the propensity score quintiles in the model, where we try to correct for the nonrandomization.

The addition of the quintiles does not change the model very much: the $R^{2}$ augments from 0.2769 to 0.2965 , the parameter estimates are almost the same in both models, the Hosmer and Lemeshow test indicates that the model has a good fit (0.1436), and there is no multicollinearity in the model. For the analysis of maximum likelihood estimates, see the Appendix.

First, we should remark that the stepwise selection mechanism chose blood cardioplegia as a significant predictor of mortality out of 20 possible variables. This variable has a $P$ value of .020 and is thus highly significant in predicting mortality. Although we corrected for the effects of age, CPB time, NYHA class, reoperations, renal failure, and active endocarditis on mortality and, moreover, we balanced the treatment groups for a whole range of variables with the propensity score, we still find a significant treatment effect.

The odds of mortality when being operated on with blood cardioplegia are $44 \%$ of the odds of mortality when operated on with crystalloid cardioplegia. Therefore patients being operated on with crystalloid cardioplegia have a more than double chance of dying after valve surgery than if blood cardioplegia is used. The 95\% confidence interval for this odds ratio is 0.218 to 0.876 .

\section{Discussion}

These results show that hospital mortality in valve operations and combined valve and coronary bypass operations can be influenced by the choice of the myocardial protection technique. In a comparable study in mainly coronary bypass operations, Loop and colleagues ${ }^{9}$ could not show this effect, although a significant reduction in morbidity was demonstrated with the use of blood cardioplegia. Our study shows that in absolute figures hospital mortality is reduced from $8.5 \%$ to $5.2 \%$ in the cohort of patients operated on with blood cardioplegia instead of crystalloid cardioplegia. The multivariate analysis revealed the use of retrograde blood 
cardioplegia as an independent predictor of hospital mortality, with an odds ratio of 0.44 and a $95 \%$ confidence interval of 0.218 to 0.876 . Therefore in the worst case patients being operated on with blood cardioplegia have a reduced chance of mortality of greater than $10 \%$ and, in the best case, a reduction of almost $80 \%$. This means that independent from any other factor, blood cardioplegia reduces hospital mortality by approximately 50\%. In addition to this, other independent factors increasing hospital mortality are age, NYHA function class, CPB time, active endocarditis, reoperations, and renal failure. Most of these factors were already identified earlier. ${ }^{11}$

Another interesting finding is that in the univariate analysis aortic crossclamp time, duration of $\mathrm{CPB}$, and the complexity of the operation are significantly related to hospital mortality. An isolated (single or multiple) valve procedure has an overall hospital mortality of $4.3 \%$, and a combined valve and coronary bypass operation has a mortality of $7.8 \%$ when the main stem is normal and a mortality of $13.6 \%$ when the left main stem is involved. In the multivariate analysis, however, aortic crossclamp time and type of operation are no longer significant predictors of hospital mortality.

It must be noted that the addition of propensity scores did not change the conclusions of the present study. The magnitude and significance of the effects of the influencing factors barely changed. No additional predictors were found, nor were predictors deleted from the model with or without propensity score quintiles included.

In addition to the choice of crystalloid or blood cardioplegia, other factors can differ between current cardioplegia techniques. These involve temperature, intermittence of delivery, and direction of flow. Two different routes of application are available, antegrade and retrograde, as well as the combination of both. Although retrograde cardioplegia is increasing in popularity, concerns have been raised about the adequacy of perfusion of the right ventricle. It was shown by Menasché and coworkers ${ }^{12}$ and our group ${ }^{13}$ that right ventricular function is adequately preserved after coronary sinus cardioplegia. Furthermore, we could show that in the presence of coronary artery obstruction, retrograde delivery was superior to antegrade delivery. ${ }^{14}$ However, Arom and associates ${ }^{15}$ evaluated the 2 different routes of cardioplegia in more than 7000 patients and found that retrograde cardioplegia alone provides myocardial protection and safety that is just as good as that provided by an antegrade-retrograde approach in either low-risk or highrisk patients.

Controversy still exists as to whether blood cardioplegia should be warm or cold. In a large randomized trial in 1700 coronary bypass operations, warm versus cold antegrade blood cardioplegia was compared, and a favorable cardiac outcome with warm heart surgery was demonstrated. ${ }^{4}$ In another randomized trial involving 1001 patients, continuous warm blood cardioplegia was shown to have similar mortality and cardiac outcome as antegrade cold crystalloid cardioplegia, but strokes and total neurologic events were greater in the warm cardioplegia group. ${ }^{16}$ In another clinical study it was proposed that optimal cardioplegia might actually be tepid $\left(29^{\circ} \mathrm{C}\right) .^{7}$

Cardioplegia was initially developed not only to protect the myocardium but also to create a quiet and bloodless surgical field. Continuous blood cardioplegia has a serious disadvantage because of limited visibility. This resulted in widespread use of the intermittent instead of continuous application of blood cardioplegia. However, it was shown ${ }^{17}$ that continuous cold blood cardioplegia results in fewer cardiac events, better left ventricular performance, and a marked improvement of right ventricular function in comparison with similar solutions of blood cardioplegia administered intermittently, independent of their means of delivery. In practice, uninterrupted delivery of blood cardioplegia is hardly possible, and therefore most procedures are done with intermittent cardioplegia delivery. This is also the case in our operations, although cardioplegia was never interrupted for longer than 10 minutes. In warm blood cardioplegia it is important that any single period of ischemia (ie, time off cardioplegia) is limited to less than 14 minutes because otherwise, adverse clinical events increase significantly. ${ }^{18}$

Basically, in coronary bypass surgery a significant lower mortality with the use of cold ${ }^{9}$ or warm ${ }^{3,5}$ blood cardioplegia than with the use of antegrade cold crystalloid cardioplegia could not be shown, in either historical ${ }^{9}$ or randomized clinical trials. ${ }^{3,5}$ In contrast, our study shows a clear influence of the type of cardioprotection on hospital mortality in valve procedures and combined valve and coronary bypass procedures. This was indicated by the findings of Chitwood and colleagues, ${ }^{19}$ who described, in an uncontrolled study of 194 patients undergoing complex cardiac procedures, a 30-day mortality rate of $3.1 \%$ with combined antegrade and retrograde cold blood cardioplegia.

In conclusion, we found that patients undergoing valvular cardiac surgery who received continuous retrograde blood cardioplegia had lower perioperative mortality than patients receiving single-dose antegrade crystalloid cardioplegia. However, the association between the use of blood cardioplegia and better results does not imply a causal relationship and certainly does not exclude the influence on hospital mortality of recent overall improvements in cardiac surgery, which cannot be traced by means of sophisticated statistical techniques.

\section{References}

1. Izzat MB, West RR, Bryan AJ, Angelini GD. Coronary artery bypass surgery: current practice in the United Kingdom. Br Heart J. 1994; $71: 382-5$. 
2. Buckberg GD. Studies of controlled reperfusion after ischemia: a series of experimental and clinical observations from the Division of Thoracic Surgery, UCLA School of Medicine. J Thorac Cardiovasc Surg. 1986;92(Suppl):483-648.

3. Jacquet LM, Noirhomme PH, Van Dyck MJ, El Khoury GA, Matta AJ, Goenen MJ, et al. Randomized trial of intermittent antegrade warm blood versus cold crystalloid cardioplegia. Ann Thorac Surg. 1999;67:471-7.

4. The Warm Heart Investigators. Randomized trial of normothermic versus hypothermic coronary bypass surgery. Lancet. 1994;353:55963.

5. Martin TD, Craver JM, Gott JP, Weintraub WS, Ramsay J, Mora CT, et al. Prospective, randomized trial of retrograde warm blood cardioplegia: myocardial benefit and neurologic threat. Ann Thorac Surg. 1994;57:298-304.

6. Hayashida N, Ikonomidis JS, Weisel RD, Shirai T, Ivanov J, Carson SM, et al. The optimal cardioplegic temperature. Ann Thorac Surg. 1994;58:961-71.

7. Hayashida N, Weisel RD, Shirai T, Ikonomidis JS, Ivanov J, Carson SM, et al. Tepid antegrade and retrograde cardioplegia. Ann Thorac Surg. 1995;59:723-9.

8. Kim YI, Herijgers P, Van Lommel A, Verbeken E, Flameng W. $\mathrm{Na}^{+} / \mathrm{H}^{+}$exchange inhibition improves post-transplant myocardial compliance in 4-hour stored donor hearts. Cardiovasc Surg. 1998;6: 67-75.

9. Loop FD, Higgins TL, Panda R, Pearce G, Estafanous G. Myocardial protection during cardiac operations. J Thorac Cardiovasc Surg. 1992; 104:608-18.

10. Rosenbaum PR, Rubin DB. The central role of the propensity score in observational studies for causal effects. Biometrika. 1983;70:41-55.
11. Flameng WJ, Herijgers P, Szecsi J, Sergeant PT, Daenen WJ, Scheys I. Determinants of early and late results of combined valve operations and coronary artery bypass grafting. Ann Thorac Surg. 1996;61:621-8.

12. Menasché P, Subayi JB, Piwnica A. Retrograde coronary sinus cardioplegia for aortic valve operations: a clinical report on 500 patients. Ann Thorac Surg. 1990;49:556-64.

13. Noyez L, Van Son JAM, Van der Werf T, Knape JT, Gimbrere J, van Asten WN, et al. Retrograde coronary sinus cardioplegia in myocardial revascularization: hemodynamic evaluation of the influence on the right-ventricular function. Thorac Cardiovasc Surg. 1992;40:20913.

14. Noyez L, Van Son AM, Van der Werf T, Knape JT, Gimbrere J, van Asten WN, et al. Retrograde versus antegrade delivery of cardioplegic solution in myocardial revascularization. J Thorac Cardiovasc Surg. 1993; 105:854-63.

15. Arom KV, Emery RW, Petersen RJ, Bero JW. Evaluation of 7000+ patients with two different routes of cardioplegia. Ann Thorac Surg. 1997;63:1619-24.

16. McLean RF, Wong BI, Naylor CD, Snow WG, Harrington EM, Gawel $\mathrm{M}$, et al. Cardiopulmonary bypass, temperature, and central nervous system dysfunction. Circulation. 1994;90:250-5.

17. Louagie YAG, Gonzalez E, Jamart J, Malhomme B, Broka S, Buche $\mathrm{M}$, et al. Assessment of continuous cold blood cardioplegia in coronary artery bypass grafting. Ann Thorac Surg. 1997;63:689-96.

18. Lichtenstein SV, Naylor CD, Feindel M, Sykora K, Abel JG, Slutsky $\mathrm{AS}$, et al. Intermittent warm blood cardioplegia: Warm Heart Investigators. Circulation. 1995;92(Suppl):II-341-6.

19. Chitwood WR, Wixon CL, Norton TO, Lust RM. Complex valve operations: antegrade versus retrograde cardioplegia? Ann Thorac Surg. 1995;60:815-8.

\section{Appendix. Analysis of maximum likelihood estimate}

\begin{tabular}{|c|c|c|c|c|c|c|c|c|}
\hline \multirow[b]{2}{*}{ Parameter } & \multicolumn{4}{|c|}{ Model with propensity score quintiles } & \multicolumn{4}{|c|}{ Model without propensity score quintiles } \\
\hline & Estimate & SE & $x^{2}$ & $P>\chi^{2}$ & Estimate & SE & $x^{2}$ & $P>\chi^{2}$ \\
\hline Intercept & -11.8038 & 1.9394 & 37.0435 & $<.001$ & -12.1844 & 1.8871 & 41.6879 & $<.001$ \\
\hline Age & 0.1071 & 0.0251 & 18.1871 & $<.001$ & 0.1060 & 0.0246 & 18.5181 & $<.001$ \\
\hline CPB & 0.0148 & 0.0033 & 20.1666 & $<.001$ & 0.0148 & 0.0032 & 22.0293 & $<.001$ \\
\hline NYHA class +1 & 0.8906 & 0.3881 & 5.2646 & .022 & 1.0934 & 0.3697 & 8.7449 & .003 \\
\hline Reoperation +1 & 0.8693 & 0.3301 & 6.9349 & .008 & 0.8343 & 0.3268 & 6.5187 & .011 \\
\hline Blood cardioplegia & -0.8278 & 0.3546 & 5.4501 & .020 & -0.8508 & 0.3308 & 6.6154 & .010 \\
\hline Quintile 5 & -0.2618 & 0.6167 & 0.1802 & .671 & & & & \\
\hline Quintile 4 & -0.5072 & 0.4991 & 1.0326 & .310 & & & & \\
\hline Quintile 3 & -0.7925 & 0.4758 & 2.7745 & .096 & & & & \\
\hline Quintile 2 & -0.8532 & 0.4676 & 3.3289 & .068 & & & & \\
\hline Renal failure & 1.1400 & 0.5852 & 3.7947 & .051 & 1.2532 & 0.5649 & 4.9217 & .0265 \\
\hline Active endocarditis & 2.4752 & 0.8377 & 8.7317 & .003 & 2.2629 & 0.8434 & 7.1990 & .007 \\
\hline
\end{tabular}

For explanation of the used statistical methods and variables, please see "Statistical Methods" section and "Prediction of Hospital Mortality: Multivariate Analysis" section. CABG, Coronary artery bypass grafting. 